\title{
Medical and Nursing Students Perceived Knowledge, Attitudes, and Practices concerning Human Immunodeficiency Virus
}

\author{
Paraniala S. C. Lui, ${ }^{1,2}$ Jeganathan Sarangapany, ${ }^{3}$ Kim Begley, ${ }^{3}$ \\ Katherine Coote, ${ }^{3}$ and Kamal Kishore ${ }^{2}$ \\ ${ }^{1}$ School of Public Health and Social Work, Faculty of Health, Queensland University of Technology, Brisbane, QLD 4059, Australia \\ ${ }^{2}$ School of Medicine, CMNHS, Fiji National University, Suva, Fiji \\ ${ }^{3}$ The Albion Centre, Directorate of Planning and Population Health SESLHD/WHO Collaborating Centre for Capacity Building and \\ Health Care Worker Training in HIV/AIDS Care, Treatment and Support, Sydney, NSW 2010, Australia
}

Correspondence should be addressed to Paraniala S. C. Lui; paranialasilascelebi.lui@student.qut.edu.au

Received 2 February 2014; Accepted 16 March 2014; Published 31 March 2014

Academic Editors: C. M. Buchalla, E. Kahan, J. Klewer, and J. Konde-Lule

Copyright (C) 2014 Paraniala S. C Lui et al. This is an open access article distributed under the Creative Commons Attribution License, which permits unrestricted use, distribution, and reproduction in any medium, provided the original work is properly cited.

\begin{abstract}
Objective. To assess medical and nursing students' knowledge, attitudes, and practices (KAP) regarding human immunodeficiency virus (HIV) in Fiji. Methods. A cross-sectional study of 275 medical and 252 nursing students that participated in a questionnaire survey on HIV KAP. Data was analysed according to their gender, program of study, and academic year. Results. The mean HIV knowledge (HK) and attitude scores were 16.0 and 41.3, respectively. Mean HK score was significantly higher in males compared to females. Significant positive correlations were found between HK and academic year for medical $(R=0.459)$ and nursing $(R=0.342)$ students and between HK and attitude scores $(R=0.196)$. The majority of students indicated fear in contracting HIV through clinical practice and felt that health care workers have the right to know a patients HIV status for their own safety. The majority would wear gloves to touch a patient if suspected of HIV. Conclusions. The study found a high level of HIV knowledge and positive attitude towards HIV patients. However, respondents also displayed negative attitudes and unacceptable practices probably due to fear. Training institutions need to ensure that students gain accurate knowledge on HIV especially on transmission routes to allay the fear of caring for HIV-infected patients.
\end{abstract}

\section{Introduction}

Human immunodeficiency virus (HIV) and acquired immunodeficiency syndrome (AIDS) are global public health problems and are becoming a threat to the South Pacific region because more than $97.0 \%$ of all infections are occurring in the developing countries and increasing every year [1]. Although the prevalence of HIV in most Pacific islands was low, the incidence of HIV in most Pacific islands continued to increase [2]. In Fiji, by the end of 2012, 482 confirmed HIV cases had been reported since the first case was diagnosed in January 1989. Adults aged 20-39 years accounted for almost $77.0 \%$ of HIV cases and heterosexual transmission reported for $91.0 \%$ of all cases [3].

The main goal of HIV and AIDS education in medical and nursing training is to equip them with the right information needed to provide effective and culturally appropriate care to their patients and at the same protect themselves against infection [4]. A number of studies have highlighted the need to enhance and integrate HIV education into the core curriculum in medical and nursing schools [4-12]. A study among Turkish nursing students found high levels of negative attitude and fear of contagion of HIV as a reason for being unwilling to care for HIV-infected patients [5]. A study among nursing students in Macedonia found that although most students had high level of HIV knowledge, a majority avoided people living with HIV (PLHIV) [6]. Another study among nursing students in Greece found that more than a third of the nursing students believe that mosquitoes can transmit HIV virus [7]. In Turkey, a study among nursing students revealed that most students still have misconceptions about HIV and that their attitudes need improvement [8]. 
In South Africa, students displayed positive attitudes and a willingness to care for PLHIV but lacked knowledge about HIV policies [9]. The majority of medical students in public and private universities in Malaysia believed that the beds of $\mathrm{HIV}$-infected patients should be marked. Such practices are discriminatory and are an infringement of the patients' right to autonomy and confidentiality [10]. Medical students in another study were found to be lacking in correct knowledge about HIV vertical transmission and effectiveness of condom use [11]. A study in Russia found that prejudicial attitudes about HIV-positive people were prevalent among medical students [12].

Medical and nursing students are future health care workers (HCWs), who may eventually find themselves working in the fields of HIV/sexually transmitted infection (STI) prevention, care, and treatment. Thus, medical and nursing students should be provided with detailed knowledge about HIV and related issues in order to provide high quality, nonjudgmental services that will engage key populations at risk of HIV [13-16]. Students can be positive role models to their peers and their communities in their attitudes towards HIV [17].

The College of Medicine, Nursing and Health Sciences of the Fiji National University, enrolls medical and nursing students from South Pacific island states including Samoa, Solomon Islands, Kiribati, Vanuatu, Cook Islands, Tahiti, Niue, and Fiji. HIV and AIDS are being taught as a component of community health in the preclinical years of their training. Medical and nursing training programs should ensure that sexual and reproductive health (SRH) curricula thoroughly cover the benefits of promoting humane attitudes and behaviour towards HIV. The knowledge and perception of these students about HIV and AIDS are unknown and required investigation. Hence, this study investigated medical and nursing students' knowledge, attitudes, and practices about HIV in one medical and two nursing training schools in Fiji. We believe the outcomes of this study will help these health care training institutions implement changes to their curriculum to improve HIV understanding among future medical doctors and nurses in Fiji and the Pacific region.

\section{Methods}

2.1. Study Design. This study was a cross-sectional descriptive study of medical and nursing students at the College of Medicine Nursing and Health sciences (CMNHS) and Sangam Nursing School in Fiji between October and November 2011.

2.2. Sample Size. Sample size was estimated at 400 participants for a confidence interval of $95.0 \%$ with a margin of error (ME) of 5.0\% using the formula $\mathrm{ME}=1 / \sqrt{ } N,(N=$ number of participants).

2.3. Data Collection and Instrument. The questionnaire consisted of four sections: sociodemographics (gender, age, course of study, and year of study), HIV knowledge, attitudes, and practices towards HIV. The knowledge section of the survey instrument is a 20 -item questionnaire combining the 18-item HIV knowledge questionnaire (HIV-KQ 18) with the two additional questions designed specifically for this study. The HIV-KQ 18 is a self-administered questionnaire which has been validated and found to be reliable [18]. The HIV KQ-18 measures the respondent's HIV knowledge related to sexual transmission and prevention of disease. The two additional questions in the survey measured knowledge in relation to, STI rates in the Pacific and taking clients' sexual history during clinic visits. We felt that these two questions will be useful in assessing the students' general knowledge about current rates of STIs in the Pacific as the current high rates of STIs in the Pacific have implications on $\mathrm{HIV}$ and the importance of taking sexual history from clients. Questions on HIV knowledge used a "true," "false," or "do not know" scale. Questions were marked as correct or incorrect. Participants responding with "do not know" or no response to a question was marked as incorrect. The total HIV knowledge scores ranged from 0 to 20 . Higher score suggests greater knowledge and, conversely, a lower score would indicate a lower general knowledge of HIV/AIDS and STI rates in Fiji.

The attitudes section comprised of 14 questions that assessed the attitudes and beliefs about PLHIV using a 4point Likert scale of "strongly agree," "agree," "disagree," or "strongly disagree." Positive attitude statements were coded with "strongly disagree $=1$ " to "strongly agree $=4$ " and negative attitude statements are the reverse. The total score for the attitude section with 14 questions ranged from 14 to 56. To compare gender and course differences, responses were dichotomised as "strongly agree" and "agree" and "strongly disagree" and "disagree."

The practices section of the questionnaire comprised 4 statements that assessed acceptable and unacceptable clinical practice when caring for HIV-infected patients that was measured on a 5-point Likert scale of "all the time," "some of the time," "not sure," "hardly ever," or "never." To compare gender and course response differences, the 5-point scale was dichotomised to "all of the time" compared with "some of the time," "not sure," "hardly ever," or "never."

The self-administered questionnaire was piloted to ensure survey's wording and clarity were apparent to all respondents prior to the actual survey. Content was reviewed before being distributed. The questionnaires were distributed and collected by program coordinators.

2.4. Procedure and Data Analysis. The data were analysed using Statistical Package for Social Science (SPSS) version 20 (Chicago, IL) statistical software. Descriptive statistics were used to describe study population. Internal reliability of the 38-item knowledge, attitude, and practices questionnaire in the study population was tested using Kuder-Richardson (KR)-20 analysis for dichotomous response scale (knowledge section) and Cronbach alpha coefficient for Likert-type scale (attitudes and practices section). Reliability coefficient of $>0.6$ was accepted as the lower limit of acceptability for the study as suggested by Hair et al. [19]. Further analysis was conducted to investigate differences by gender, program of study, and relationship between HIV knowledge with year of study. 
TABle 1: Demographic characteristics $(N=527)$.

\begin{tabular}{lcc}
\hline $\begin{array}{l}\text { Respondent } \\
\text { characteristics }\end{array}$ & Variables & Number (\%) \\
\hline Gender & Female & $324(61.5)$ \\
& Others & $154(29.2)$ \\
\hline & $18-22$ & $49(9.3)$ \\
Age (years) & $23-27$ & $425(80.6)$ \\
& $>28$ & $96(18.2)$ \\
Mean age $( \pm$ SD) & $21.1 \pm 2.2$ & $6(1.2)$ \\
years & Nursing & \\
Programme of & Medical & $252(47.8)$ \\
study & Fiji & $275(52.2)$ \\
\hline & Solomon Islands & $444(84.3)$ \\
& Tonga & $21(4.0)$ \\
Nationality & Samoa & $18(3.4)$ \\
& Vanuatu & $16(3.0)$ \\
& Others & $9(1.7)$ \\
\end{tabular}

Mean HIV knowledge scores were compared between groups using the one-way analysis of variance (ANOVA) and the independent sample $t$-test. Attitudes and practice responses were compared between groups using the chi-square or Fisher's exact where appropriate. Pearson's correlation was used to investigate the relationship of HIV knowledge score and attitude score with year of course. Pearson's correlation was also used to investigate association between HIV knowledge and attitude scores. All test were two sided and a $P$ value of $<0.05$ was taken as statistically significant.

The study was approved by the CMNHS Health Research Ethics Committees of the Fiji National University. All participants were consented prior to participation in the study.

\section{Results}

Of the 800 questionnaires distributed to the medical and nursing students, 527 were received giving the survey a response rate of $65.9 \%$. Table 1 summarizes the demographic characteristics of participants.

A total of 275 medical (years 1-6) students and 252 nursing (years 1-3) students participated in the study. More than half the medical students 149 (54.2\%) were females; males were 112 (40.7\%) and 14 (5.1\%) were "other." More than two-third of the nursing students were females 175 (69.4\%), 42 (16.7\%) were males, and 35 (13.9\%) were "other" (includes transvestite, transgender, and transsexual). The majority (202 $(73.5 \%))$ of the medical students were from the junior classes (years 1-3), while 73 (26.5\%) were from the senior classes (years $4-6)$. The majority (215 (85.2\%)) of nursing students were from years 1 and 2, while only $37(14.8 \%)$ were final-year students. Low representation from the senior classes was due to community and clinical rotation coinciding with the study.
All three sections of the questionnaire achieved the lower limit of reliability set for the study at 0.6. The 20item knowledge section achieved KR coefficient of 0.685. Subanalysis found the HIV KQ-18 yielded KR coefficient of 0.675. Addition of the two questions on STI rates in the pacific and taking client's sexual history to the HIV KQ-18 did not decrease the KR coefficient of the HIV KQ-18. The Cronbach alpha coefficients for attitudes and practices section were 0.624 and 0.679 , respectively. All questions were retained for the analysis as deletion of question based on removal of question with item-to-total score correlation of $R<0.2 \mathrm{did}$ not alter the reliability coefficients significantly.

The mean total HIV knowledge score was $16.0 \pm 2.9$ (80.0\%). The scores ranged from 0 to 20 . Majority (405 $(76.9 \%))$ had at least 15 questions correct. Twenty (3.8\%) participants scored 20 and two participants scored zero marks. Significant differences were found between genders $\left(F_{(2,524)}=11.69, P<0.0001\right)$. No difference in mean HIV knowledge score was found between medical and nursing students (Table 2). Significant positive correlations were found between HIV knowledge and year of study (medical: $R=$ $0.459, P<0.0001$; nursing: $R=0.342, P<0.0001)$.

The mean attitude score was $41.3 \pm 4.7$ (range $24-53$ ). No differences in attitude scores were found between gender and course of study (Table 2). Significant positive correlation $(R=$ $0.235, P<0.0001)$ was found between attitude score and year of study among nursing students. No correlation was found among medical students between attitude score and year of study $(R=0.074, P=0.226)$.

Significant positive correlation was found between HIV knowledge score and attitude score in the cohort $(R=$ $0.196, P<0.0001)$. Subanalysis also found significant positive correlation between HIV knowledge and attitude scores within groups: medical $(R=0.136, P=0.012)$ and nursing $(R=0.267, P<0.0001)$.

Table 3 displays analysis of individual questions relating to HIV knowledge with gender and program of study comparisons. The highest scored question among students was regarding having sex with more than one partner increasing a person's chance of being infected with HIV (97.2\%). The lowest scored question was that suggesting that a natural skin condom works better against HIV compared to a latex condom (56.2\%). Overall, 15 of the 20 questions achieved at least a score of $75.0 \%$. Of these, only 4 questions achieved a score $>90.0 \%$.

Gender comparisons found 6 of the $20(30.0 \%)$ questions to be significantly different. Those who identified themselves as "others" scored lowest in 5 of the 6 questions and females scored lowest for one question. Ninety-one (28.1\%) female participants were unaware that a woman is at risk of HIV infection if she is having anal sex with a man. Significantly more male respondents compared with females and "others" appeared to be more knowledgeable on the following: coughing and sneezing do not transmit $\operatorname{HIV}\left(\chi^{2}=7.26, P=0.027\right)$, HIV contracts through anal sex $\left(\chi^{2}=9.03, P=0.011\right)$, HIV is transmitted when sharing a glass of water with an HIV-infected person $\left(\chi^{2}=7.07, P=0.029\right)$, pulling out the penis before climaxing keeps a woman from getting HIV 
TABLE 2: Summary of HIV knowledge and attitude scores.

\begin{tabular}{|c|c|c|c|c|c|c|}
\hline & Mean HIV knowledge score (SD) & Test value & $P$ value & Mean attitude score (SD) & Test value & $P$ value \\
\hline Whole cohort $(n=527)$ & $16.0(2.9)$ & & & $41.3(4.7)$ & & \\
\hline \multicolumn{7}{|l|}{ Gender } \\
\hline Female $(n=324)$ & $17.5(1.7)$ & & & $41.5(4.8)$ & & \\
\hline Male $(n=154)$ & $18.1(1.4)$ & & & $41.1(4.5)$ & & \\
\hline Other $(n=49)$ & $16.9(2.3)$ & $F=11.69$ & $<0.0001$ & $40.4(5.0)$ & $F=1.43$ & 0.241 \\
\hline \multicolumn{7}{|l|}{ Course } \\
\hline Medical $(n=275)$ & $15.8(3.1)$ & & & $41.2(4.5)$ & & \\
\hline Nursing $(n=252)$ & $16.1(2.7)$ & $t=-0.927$ & 0.354 & $41.4(5.0)$ & $t=-0.551$ & 0.582 \\
\hline
\end{tabular}

$\left(\chi^{2}=14.61, P=0.001\right)$, and contracting HIV by sitting in a hot tub or a swimming pool with a person who has HIV $\left(\chi^{2}=6.69, P=0.035\right)$ and using Vaseline oil with condoms will not lower the chance of getting $\operatorname{HIV}\left(\chi^{2}=6.42\right.$, $P=0.040$ ) (Table 3).

Comparisons between medical and nursing knowledge scores found 6 of the 20 questions $(30.0 \%)$ to be significantly different. Of these, nurses scored significantly higher in 4 of the questions. More nurses compared with medical students incorrectly thought that it was safe to practice pulling the penis out before climaxing $\left(\chi^{2}=9.01, P=0.003\right)$ and that all $\mathrm{HIV}$-infected pregnant women will deliver $\mathrm{HIV}$-infected babies ( $\left.\chi^{2}=4.48, P=0.037\right)$. Significantly more nurses compared with medical students answered correctly to the statement that there is a female condom that can help protect a woman from getting HIV (86.9\% versus $77.5 \%, P=0.006$ ) and that taking a HIV test one week after sex will not tell a person that they are infected $(72.2 \%$ versus $62.9, P=$ 0.026). With regards to STI rates in the Pacific, $83.3 \%$ of nurses compared to $72.0 \%$ of medical students $(P=0.002)$ indicated correctly that STI rates are high in the region. Similarly, significantly more nurses compared to medical students $(91.7 \%$ versus $65.1 \%, P<0.0001)$ thought that a client's sexual history should be recorded during every clinic visit (Table 3).

A summary of responses to students' attitudes and beliefs about HIV and AIDS is displayed in Table 4. The majority $(77.6 \%)$ indicated that they were afraid of contracting HIV through clinical practice. About a third of the students (30.9\%) believed that HIV and STIs are a punishment for immoral behaviour and $60.0 \%$ of them believed that key at-risk populations are responsible for spreading HIV. Only a small proportion of respondents believed that those who contracted HIV through illegal behaviour should not be treated in government run facilities (6.5\%) and that there is no point in treating a person with AIDS as they will die anyway $(4.2 \%)$. The majority of the students $(93.5 \%)$ agreed that they would like to know their HIV status. Most respondents $(95.6 \%)$ would visit a friend's house that has an HIV-infected member, would care for someone living with HIV at home $(80.8 \%)$, purchase food from a shop where a PLHIV was working (79.5\%), and share food utensils with a family member who had HIV (78.0\%).

Gender and course comparisons found 3 and 5 of the 14 questions, respectively, to be significantly different.
Those who identified themselves as "others" (18.4\%) believed that people who contracted HIV/STIs through illegal behaviour should not be treated at government run hospitals and clinics compared with $7.8 \%$ males and only $4.0 \%$ female participants $\left(\chi^{2}=15.18, P=0.001\right)$. More male students $(30.5 \%)$ and female students $(29.3 \%)$ would not go to a local clinic to be tested for HIV for the fear of others knowing the result compared with only $10.2 \%$ who identified themselves as "others" $\left(\chi^{2}=8.48, P=0.014\right)$. A majority of female students $(84.0 \%)$ compared with $78.6 \%$ males and $67.3 \%$ "others" indicated that they would care for a HIV positive relative at home $\left(\chi^{2}=8.29, P=0.016\right)$. More nursing compared with medical students $(39.7 \%$ versus $22.9 \%)$ believed that HIV is a punishment for immoral behaviour $\left(\chi^{2}=17.30, P<0.0001\right)$. Additionally, more nursing students compared with medical students $(65.1 \%$ versus $55.3 \%$ ) believed that sex workers, youth, and other vulnerable groups were responsible for the transmission of HIV and STIs $\left(\chi^{2}=5.27, P=0.022\right)$. More medical compared to nursing students (28.0\% versus $19.0 \%)$ indicated that they would treat themselves if they had a problem in their genitals or private parts before going to a clinic $\left(\chi^{2}=5.83\right.$, $P=0.016)$. More medical compared to nursing students (84.0\% versus $77.4 \%$ ) would care for a HIV positive relative in their home $\left(\chi^{2}=3.72, P=0.053\right)$. A majority of nursing $(83.3 \%)$ compared to medical students $(73.1 \%)$ would share food utensils with an HIV-infected relative $\left(\chi^{2}=8.04\right.$, $P=0.005)$.

Table 5 displays a summary of student's perceived practices towards patients suspected of having HIV. The majority (83.9\%) of participants stated that they would wear gloves to touch a patient who had or was suspected of having HIV. The majority of participants responded that they would wear gloves when taking blood from any patient (92.7\%) and when working with blood (94.5\%). The majority (85.7\%) stated that they would wear gloves when changing sheets of a patient with HIV. More female and male compared with "others" indicated that they would wear gloves all the time when taking blood from any patient $(95.5 \%$ versus $91.6 \%$ versus $\left.79.6 \% ; \chi^{2}=16.33, P<0.0001\right)$ and when working with blood (96.3\% versus $94.2 \%$ versus $83.7 \% ; \chi^{2}=13.09, P<0.0001$ ), respectively. The majority of nursing (92.5\%) compared with medical students $(79.6 \%)$ indicated that they would wear gloves all the time even when changing the bed sheets of a patient living with $\operatorname{HIV}(P<0.0001)$. 


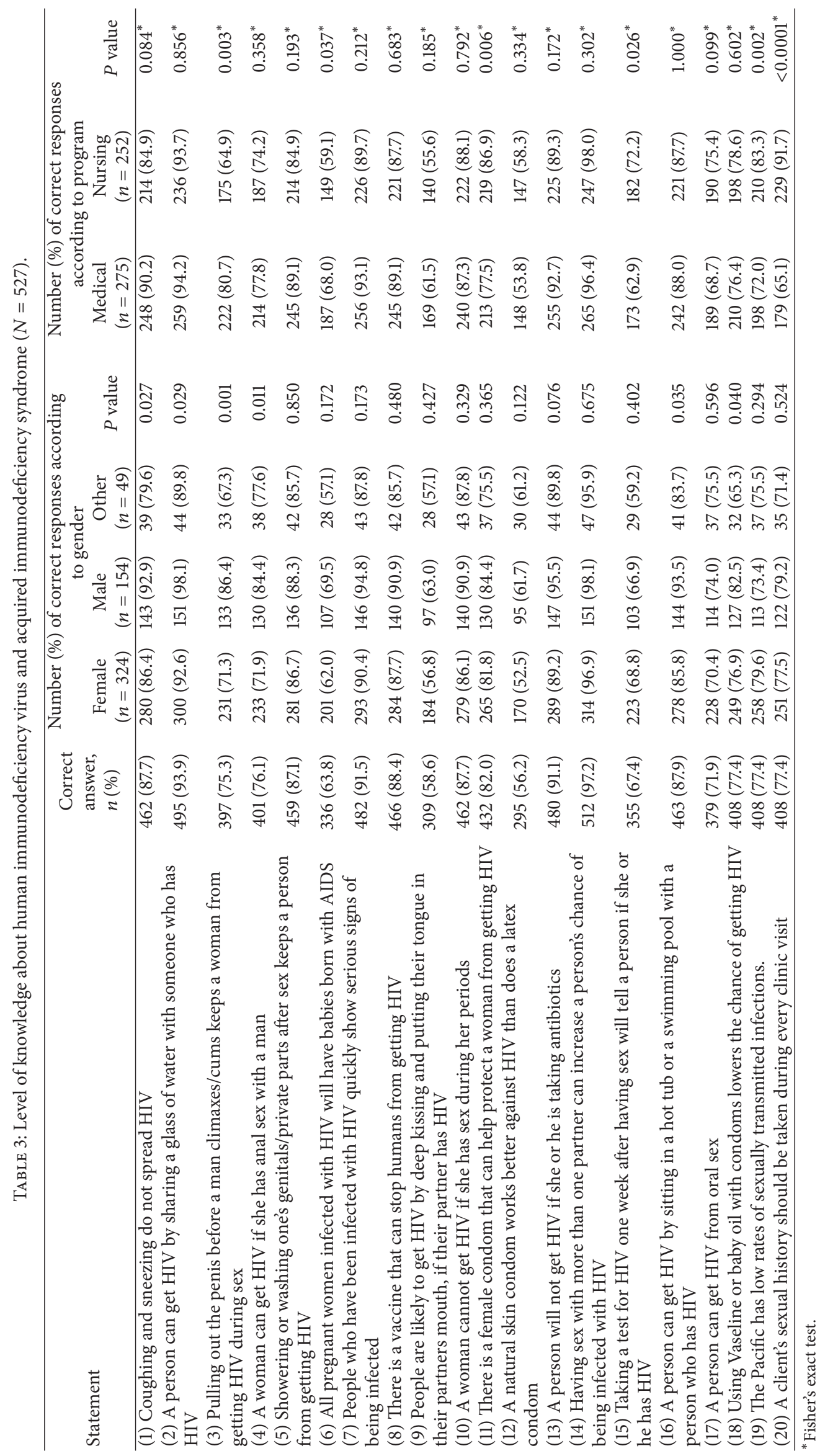




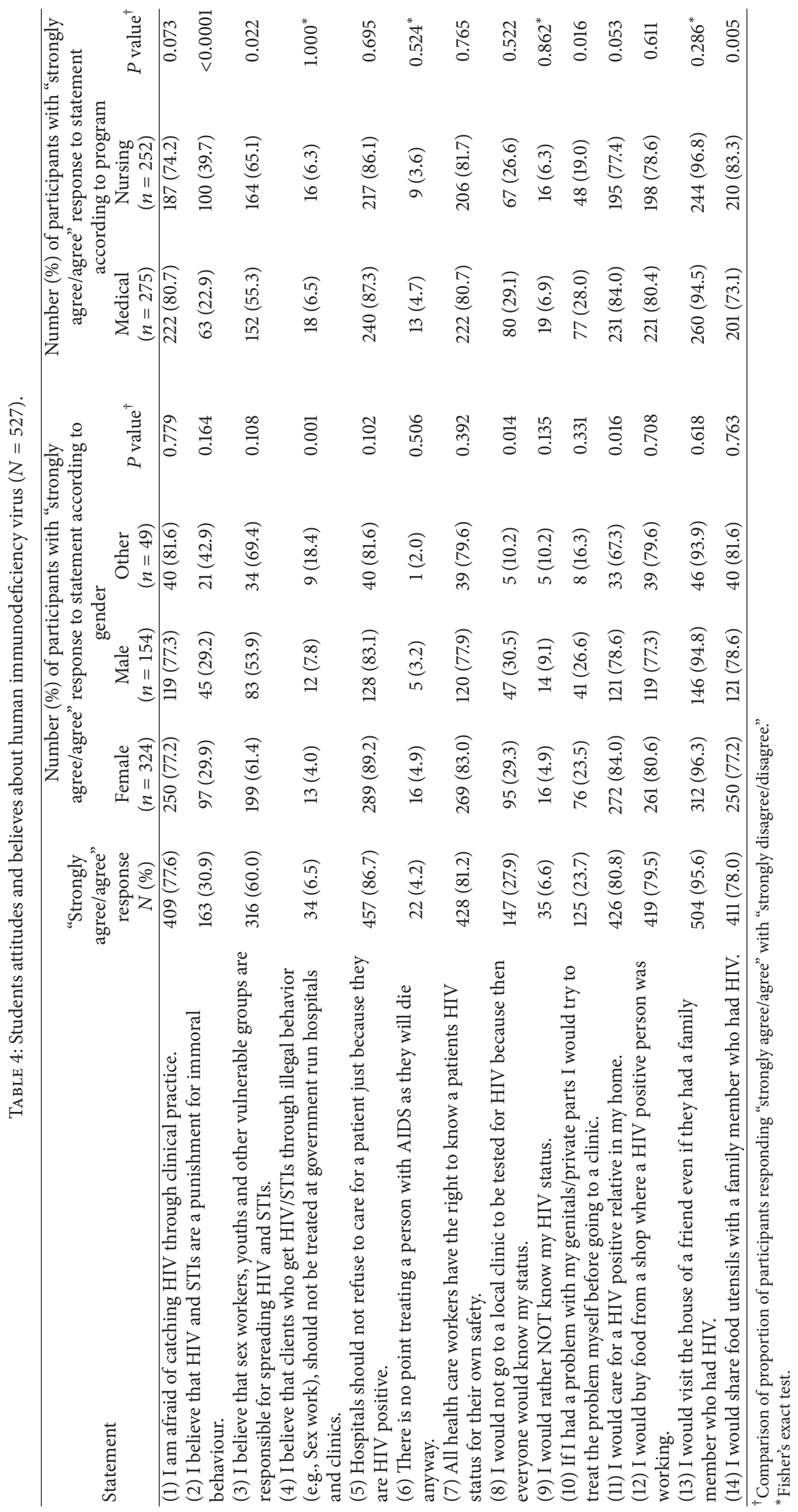


TABLE 5: Students perceived practice towards patients suspected of having HIV $(N=527)$.

\begin{tabular}{|c|c|c|c|c|c|c|c|c|}
\hline \multirow{2}{*}{$\begin{array}{l}\text { Statement: } \\
\text { when on clinical } \\
\text { placement, I would } \\
\text { wear gloves if I had to }\end{array}$} & \multirow{2}{*}{$\begin{array}{l}\text { "All the time" } \\
\text { response } \\
N(\%)\end{array}$} & \multicolumn{4}{|c|}{$\begin{array}{c}\text { Number (\%) of respondents practice "all the } \\
\text { time" according to gender }\end{array}$} & \multicolumn{3}{|c|}{$\begin{array}{c}\text { Number (\%) of respondents practice "all the } \\
\text { time" according to program }\end{array}$} \\
\hline & & $\begin{array}{l}\text { Female } \\
(n=324)\end{array}$ & $\begin{array}{c}\text { Male } \\
(n=154)\end{array}$ & $\begin{array}{l}\text { Other } \\
(n=49)\end{array}$ & $P$ value $^{\dagger}$ & $\begin{array}{l}\text { Medical } \\
(n=275)\end{array}$ & $\begin{array}{l}\text { Nursing } \\
(n=252)\end{array}$ & $P$ value $^{\dagger}$ \\
\hline $\begin{array}{l}\text { Touch a patient who } \\
\text { had or was suspected } \\
\text { of having HIV }\end{array}$ & $442(83.9)$ & $274(84.6)$ & $130(84.4)$ & $38(77.6)$ & 0.449 & $233(84.7)$ & 209 (82.9) & $0.636^{*}$ \\
\hline $\begin{array}{l}\text { Take blood from any } \\
\text { patient }\end{array}$ & $489(92.7)$ & $309(95.4)$ & $141(91.6)$ & $39(79.6)$ & $<0.0001$ & $254(92.4)$ & $235(93.3)$ & $0.738^{*}$ \\
\hline Work with blood & $498(94.5)$ & $312(96.3)$ & $145(94.2)$ & $41(83.7)$ & 0.001 & $260(94.5)$ & $238(94.4)$ & $1.000^{*}$ \\
\hline $\begin{array}{l}\text { Change the sheets of a } \\
\text { patient who has HIV }\end{array}$ & $452(85.7)$ & $283(87.3)$ & $131(85.1)$ & $38(77.6)$ & 0.180 & 219 (79.6) & $233(92.5)$ & $<0.0001^{*}$ \\
\hline
\end{tabular}

†Comparison of proportion of participants who responded "all the time" with those who responded "some of the time," "not sure," "hardly ever," or "never."

* Fisher's exact test.

\section{Discussion}

The study aimed to assess the KAP towards HIV and it provided important and interesting insights into the knowledge, attitudes, and practices of medical and nursing students at the health care training institutions in Fiji. The study found a high level of HIV knowledge and associated positive attitudes toward PLHIV. The mean HK score of $80.0 \%$ in the whole cohort was high considering that the cohort was skewed towards preclinical students. Mean HIV knowledge scores and comparison of proportion of respondents with correct answers were significantly higher in males compared with the rest. Contradictory reports have been published previously regarding gender differences $[7,20]$. No significant difference was found in $\mathrm{HK}$ score between nurses and medical students. However, when the proportion of respondents with correct responses was compared, almost a third of questions were significantly different with nurses performing better in the majority. A positive moderate correlation was found for HIV knowledge scores with the year of study for both medical and nursing groups. This may indicate that the current course structure in the training institutes in Fiji is favourable to acquiring knowledge. Similarly, higher knowledge was reported among clinical medical student compared to preclinical students in Malaysia and senior year medical students compared to junior students in Turkey [21, 22]. Furthermore, knowledge and attitude showed positive correlation among this cohort of students. Similar findings of significant association between knowledge and attitude among nurses and medical students have been reported recently [7, 21, 22]. It is important that positive attitudes prevail as the health of the patient they will be treating will be affected if there is lack of empathy. The study also found significant proportion of students retained misconceptions about important aspects of HIV transmission including vertical transmission, deep kissing, and oral sex. Additionally, about $44.0 \%$ of the respondents believed that natural skin is more effective than latex condoms in preventing HIV. Furthermore, the study also revealed that a significant proportion of the students also had misconceptions regarding HIV diagnosis, including having an HIV test within one week of risk behaviour will tell if a person has HIV and sexual history taking is not important during clinic visits. These findings are reflected in similar studies of medical and nursing students in the United States of America (USA), Nigeria, India, and elsewhere [14, 17, 2227].

The attitudes and beliefs of students towards HIV revealed that almost a third of the respondents believed that HIV is a punishment for immoral behaviour and more than half of the students believe that sex workers, youths, and key at-risk populations were responsible for spreading HIV. Furthermore, the majority of respondents was afraid of contracting HIV during clinical practice and would wear latex gloves when touching an HIV-infected patient. It is over three decades since the start of the epidemic and fear of contagion in this cohort of medical and nursing students was found to be still highly prevalent and the reasons for the ongoing fear need further investigation. Similar findings have been reported in studies among medical students in the USA, Canada, Turkey, and China [28-32]. Fear of contracting HIV through clinical practice indicates overestimation of occupational risk that will have negative effects on good clinical practice resulting in compromise in care and comfort provided to patients. Fear can be allayed through education and in particular education on risk of occupational exposure in particular transmission and nontransmission routes. Evidence of occupationally acquired HIV infection is rare compared with transmission of infections such hepatitis B and this needs to be highlighted to students [28]. Negative attitudes held by future professionals can contribute to continued stigma and discrimination towards PLHIV and key at-risk populations, a recognized barrier to universal access and prevention of new infections in Fiji and the Pacific [33]. Interestingly, the majority of students believe the misconception that all health professionals have the right to know a patient's HIV status for their own safety. This is contradictory to the Fiji HIV Decree which promotes universal access without prejudice and rights of patients to confidentiality [34]. It may also indicate a lack of knowledge about HIV legislation in Fiji.

More than half of the students expressed willingness to care for a close relative, buy food from a shop owned 
by an HIV positive person, and share food utensils with a family member who had HIV. Our finding is in contrast to that of Turhan and colleagues, who found that almost half of medical, dentistry, and medical technology students in Turkey would not touch or live in the same house with HIV patient [22]. However, another study of nursing students in Turkey noted that students' feelings were sometimes based on the "concept of professional and personal responsibility" such as empathy and being friendly to PLHIV rather than positive attitudes [5]. This could be a possible explanation for the finding in this study; given the high rates of stigmatisation and discrimination in the Pacific Islands, the students reported willingness to care for close relatives with HIV in this study, which may be related to shared cultural values concerning the importance of the extended family and the community, common to Fiji and other small Pacific Island countries.

\section{Limitations}

The generalizability of the findings of this study to all medical and nursing students in Fiji may be limited by some aspects of the study design, such as the nonrandom sampling employed and the low representation of participants from the senior students at these schools. The sampling method employed to recruit participants is known to introduce volunteer bias among participants [35]. The sample for the study is skewed towards preclinical years. Furthermore, knowledge, attitudes, and practices were assessed by a cross-sectional survey and it is possible that some questions or statements could have been misinterpreted by the respondents. Finally, the validated survey used to assess the knowledge section HIV KQ-18 is a shorter version of the HIV KQ-45 which is more comprehensive [18]. The HIV KQ-18 does not assess transmission by other vectors and does not attempt to assess knowledge regarding natural history, clinical course, or treatment, which is required for medical and nursing. Finally, the attitude and practice section used a tool with face validity which is subjective. However, the questions used in the study have been used in other studies and we found reliability to be acceptable which suggest that useful valid information has been collected in the study [36].

\section{Conclusion}

While this study highlighted areas of good knowledge as well as positive attitudes and beliefs among medical and nursing students concerning HIV and $\mathrm{SH}$, it also identified important gaps in understanding and the potential for stigmatising mindsets among students. The results point to the need for health care training institutions to examine and enhance their HIV and SH related curriculum to emphasize the vulnerability of HIV-infected subjects and their protection through human rights act. Greater emphasis should be given to the exposure of medical and nursing students to clinical care of HIV patients as part of the curriculum. Medical and nursing students who will be providing HIV and $\mathrm{SH}$ care and treatment should have comprehensive HIV knowledge and should be equipped to integrate humane attitudes into their clinical practice. Further study is required to examine how the reported attitudes and knowledge of medical and nursing students translate into their clinical practice and with a wider representative sample of students from the health care training institutions in Fiji.

\section{Conflict of Interests}

The authors declare that there is no conflict of interests regarding the publication of this paper.

\section{Acknowledgments}

The authors are grateful to all the students who have participated in this study. This study was funded by AusAID through the Australian Consortium for HIV in Asia and Pacific.

\section{References}

[1] UNAIDS, "Global report: UNAIDS report on the global AIDS epidemic 2012," Geneva, Switzerland, 2012, http://www.unaids .org/en/resources/publications/2012/name,76121,en.asp.

[2] UNAIDS, "HIV in Asia and the Pacific, UNAIDS report 2013," Bangkok, Thailand, 2013, http://www.unaids.org/en/media/ unaids/contentassets/documents/unaidspublication/2013/2013_ HIV-Asia-Pacific_en.pdf.

[3] Fiji National AIDS Committee, "Fiji global AIDS response progress report 2012," Geneva, Switzerland, 2012, http://www .unaids.org/en/dataanalysis/knowyourresponse/countryprogressreports/2012countries/ce_FJ_Narrative_Report.pdf.

[4] V. C. Li, B. L. Cole, S. Z. Zhang, and C. Z. Chen, "HIVrelated knowledge and attitudes among medical students in China," AIDS Care: Psychological and Socio-Medical Aspects of AIDS/HIV, vol. 5, no. 3, pp. 305-312, 1993.

[5] H. A. Bektaş and Ö. Kulakaç, "Knowledge and attitudes of nursing students toward patients living with HIV/AIDS (PLHIV): a Turkish perspective," AIDS Care: Psychological and SocioMedical Aspects of AIDS/HIV, vol. 19, no. 7, pp. 888-894, 2007.

[6] V. Prodanovska-Stojčevska, R. Isjanovska, and E. PopovaRamova, "Knowledge of HCV infection among nursing students of the medical college of bitola," Arhiv za Higijenu Rada $i$ Toksikologiju, vol. 61, no. 2, pp. 197-201, 2010.

[7] C. Ouzouni and K. Nakakis, "HIV/AIDS knowledge, attitudes and behaviours of student nurses," Health Science Journal, vol. 6, no. 1, pp. 129-150, 2012.

[8] S. Akin, B. Mendi, O. Mendi, and Z. Durna, "Turkish nursing students' knowledge of and attitudes towards patients with HIV/AIDS," Journal of Clinical Nursing, vol. 22, no. 23-24, pp. 3361-3371, 2013.

[9] O. Sehume, L. Zungu, and M. Hoque M, "Attitudes and willingness of nursing students towards caring for patients infected with HIV in South Africa," IFE PsychologIA, vol. 20, no. 2, pp. 12-20, 2012.

[10] K. K. Choy, T. J. Rene, and S. A. Khan, "Beliefs and attitudes of medical students from public and private universities in Malaysia towards individuals with HIV/AIDS," The Scientific World Journal, vol. 2013, Article ID 462826, 8 pages, 2013.

[11] N. Han and A. Htet, "Knowledge and attitude of HIV/AIDS infection among medical students," International Journal of Collaborative Research on Internal Medicine and Public Health, vol. 4, no. 4, pp. 317-326, 2012. 
[12] D. A. Bikmukhametov, V. A. Anokhin, A. N. Vinogradova, W. R. Triner, and L.-A. McNutt, "Bias in medicine: a survey of medical student attitudes towards HIV-positive and marginalized patients in Russia, 2010," Journal of the International AIDS Society, vol. 15, no. 2, Article ID 17372, 2012.

[13] P. Weerakoon, M. K. Jones, R. Pynor, and E. Kilburn-Watt, "Allied health professional students' perceived level of comfort in clinical situations that have sexual connotations," Journal of Allied Health, vol. 33, no. 3, pp. 189-193, 2004.

[14] S. Malhotra, A. Khurshid, K. A. Hendricks, and J. R. Mann, "Medical school sexual health curriculum and training in the United States," Journal of the National Medical Association, vol. 100, no. 9, pp. 1097-1106, 2008.

[15] S. A. Vollmer and K. B. Wells, "How comfortable do first-year medical students expect to be when taking sexual histories?" Medical Education, vol. 22, no. 5, pp. 418-425, 1988.

[16] WHO, "Enhancing the role of medical schools in STI/HIV and TB control," Chennai, India, 2000, http://whqlibdoc.who. int/searo/2000/SEA_TB_228.pdf.

[17] C. A. Daniyam, P. A. Agaba, and E. I. Agaba, "Acceptability of voluntary counselling and testing among medical students in Jos, Nigeria," Journal of Infection in Developing Countries, vol. 4, no. 6, pp. 357-361, 2010.

[18] M. P. Carey and K. E. E. Schroder, "Development and psychometric evaluation of the brief HIV knowledge questionnaire," AIDS Education and Prevention, vol. 14, no. 2, pp. 172-182, 2002.

[19] J. E. Hair, R. E. Anderson, R. L. Tatham, and W. C. Black, Multivariate Data Analysis, Prentice-Hall, New Jersey, NJ, USA, 5th edition, 1998.

[20] H. Robb, E. D. Beltran, D. Katz, and B. Foxman, "Sociodemographic factors associated with AIDS knowledge in a random sample of university students," Public Health Nursing, vol. 8, no. 2, pp. 113-118, 1991.

[21] B. H. Chew BH and A. T. Cheong, "Assessing HIV/AIDS knowledge and stigmatizing attitudes among medical students in Universiti Putra Malaysia," The Medical Journal of Malaysia, vol. 68 , no. 1, pp. 24-29, 2013.

[22] O. Turhan, Y. Senol, T. Baykul, R. Saba, and A. Yalçin, "Knowledge, attitudes and behaviour of students from a medicine faculty, dentistry faculty, and medical technology Vocational Training School toward HIV/AIDS," International Journal of Occupational Medicine and Environmental Health, vol. 23, no. 2, pp. 153-160, 2010.

[23] A. S. Chauhan, M. A. Hussain, S. Pati, S. Nallala, and J. Mishra, "Knowledge and attitudes related to HIV/AIDS among medical and allied health sciences students," Indian Journal of Community Health, vol. 23, no. 2, pp. 96-98, 2011.

[24] G. R. Najem and E. I. Okoye Okuzu, "International comparison of medical students' perceptions of HIV infection and AIDS," Journal of the National Medical Association, vol. 90, no. 12, pp. 765-774, 1998.

[25] S. Pita-Fernández, B. Rodríguez-Vazquez, and S. Pertega-Diaz, "Attitudes of nursing and auxiliary hospital staff toward HIV infection and AIDS in Spain," Journal of the Association of Nurses in AIDS Care, vol. 15, no. 3, pp. 62-69, 2004.

[26] O. O. Rotimi and O. O. Oluwafemi, "Knowledge and attitudes of students in a Caribbean medical school towards HIV/AIDS," African Journal Biomedical Research, vol. 11, no. 2, pp. 137-143, 2008.

[27] Y. Samant, R. Manheshwar, L. Sankhe, and D. L. Parker, "HIV-related knowledge and attitude among first year medical students in Mumbai, India," International Electronic Journal of Health Education, vol. 9, pp. 13-24, 2005.

[28] J. A. Johnson, A. E. Campbell, C. H. Toewe, and B. J. Bell, "Knowledge and attitudes about AIDS among first- and secondyear medical students," AIDS Education and Prevention, vol. 2, no. 1, pp. 48-57, 1990.

[29] S. Hoffart, G. M. Ibrahim, R. A. Lam, E. P. Minty, M. Theam, and J. P. Schaefer, "Medical students' attitudes towards treating patients with HIV: a 12-year follow-up study," Medical Teacher, vol. 34, no. 3, p. 254, 2012.

[30] E. Nazik, S. Arslan, F. Özdemir, and S. Apay, “Turkish nursing students' attitudes about patients living with HIV/AIDS," Sexuality and Disability, vol. 30, no. 4, pp. 433-439, 2012.

[31] Y. Li, C. S. Scott, and L. Li, "Chinese nursing students' HIV/AIDS knowledge, attitudes, and practice intentions," Applied Nursing Research, vol. 21, no. 3, pp. 147-152, 2008.

[32] B. Qu, Y. Zhang, H. Guo, and G. Sun, "Relationship between HIV/AIDS knowledge and attitude among student nurses: a structural equation model," AIDS Patient Care and STDs, vol. 24, no. 1, pp. 59-63, 2010.

[33] P. S. Lui, J. Sarangapany, K. Begley, R. Musson, S. Ram S, and K. Kishore, "Knowledge, attitudes and behaviours of health care workers towards clients of sexual health services in Fiji," Sexual Health, vol. 9, no. 4, pp. 323-327, 2012.

[34] The Government of Fiji, "HIV/AIDS decree 2011 (Decree no. 5 of 2011)," Suva, fiji, 2011, http://www.fiji.gov.fj/getattachment/65656c4b-cbc9-4a48-97a4-6ce35f2612fd/Decree-No -38_2011-HIV-AIDS-(Amendment)-Decree-20.aspx.

[35] S. B. Hulley, S. R. Cummings, W. S. Browner, D. B. Grady, and T. B. Newman, Designing Clinical Research, Lippincott Williams and Wilkins, Philadelphia, Pa, USA, 4th edition, 2001.

[36] K. R. Murphy and C. O. Davidschofer, Psychological Testing: Principles and Applications, Pearson/Prentice Hall, Upper Saddle River, NJ, USA, 6th edition, 2005. 


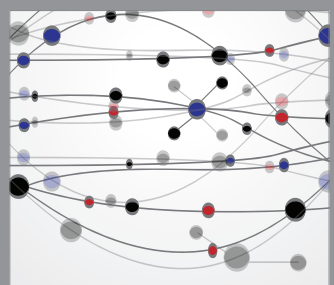

The Scientific World Journal
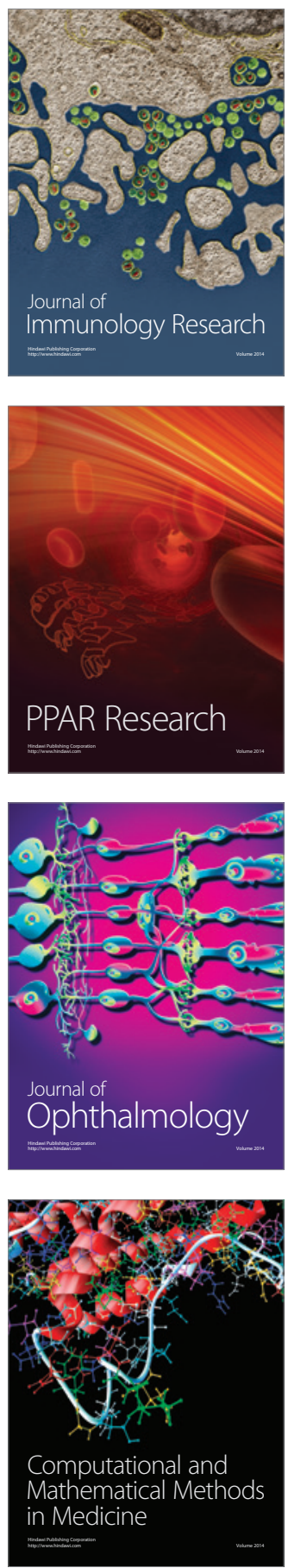

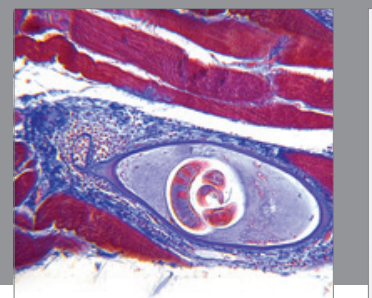

Gastroenterology

Research and Practice
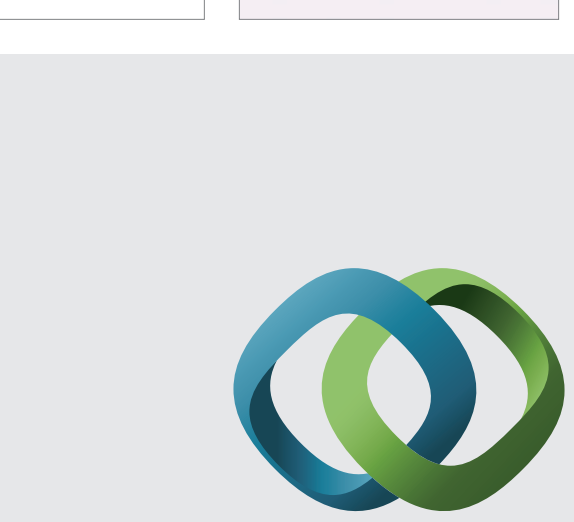

\section{Hindawi}

Submit your manuscripts at

http://www.hindawi.com
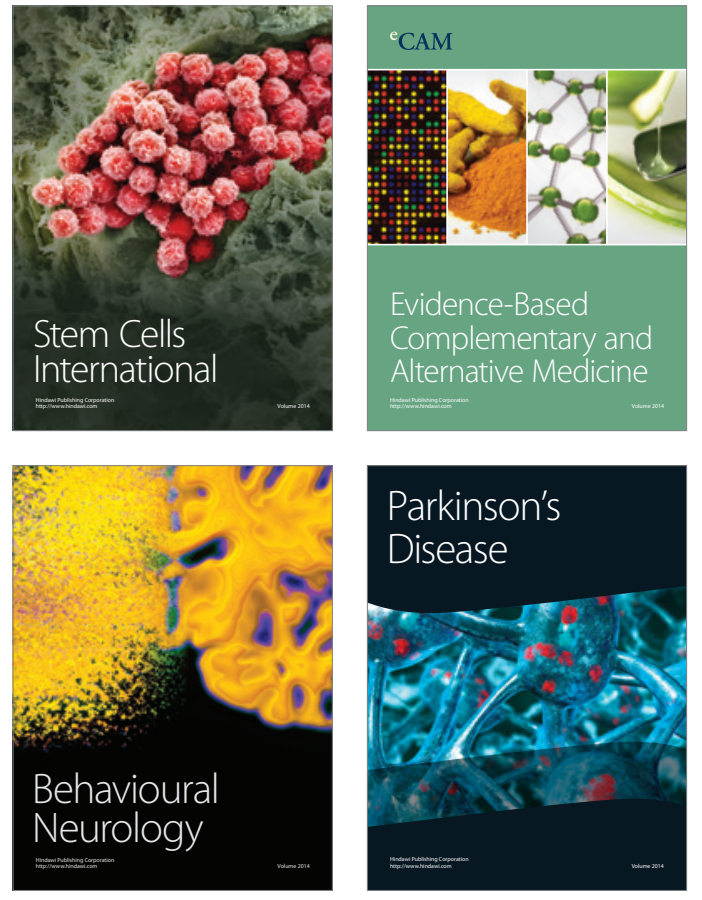
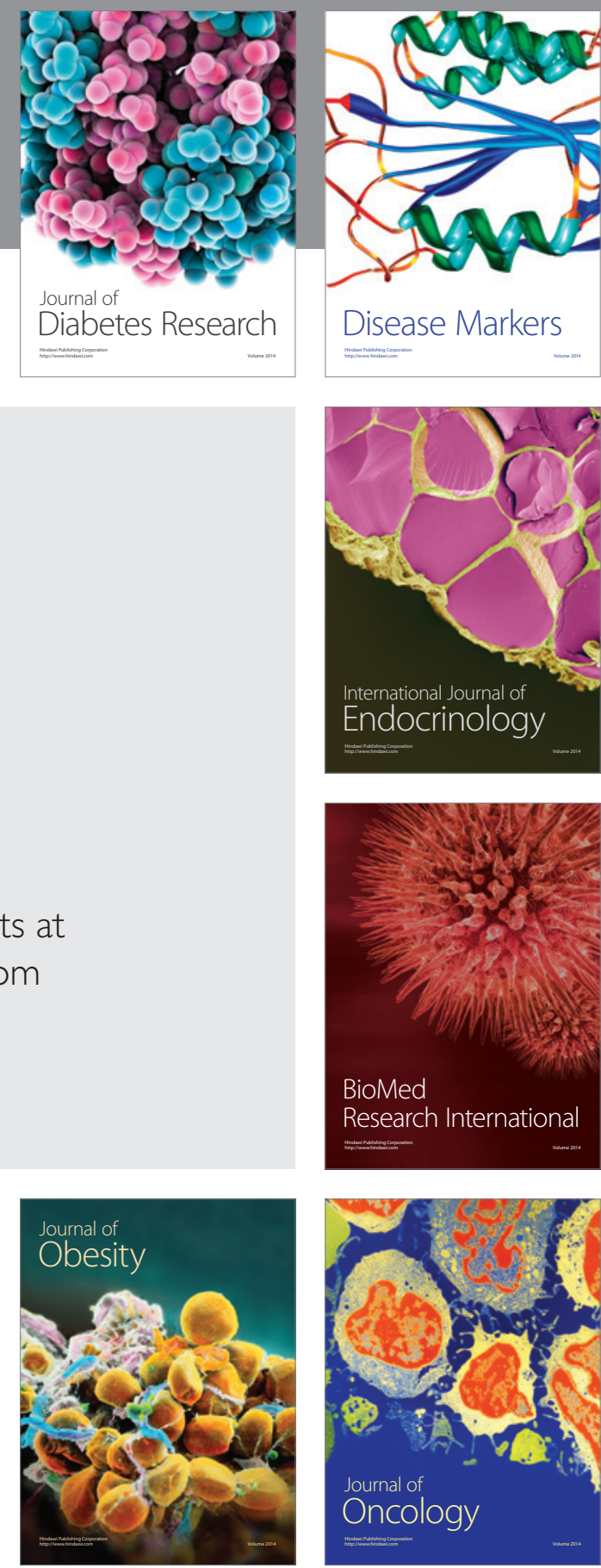

Disease Markers
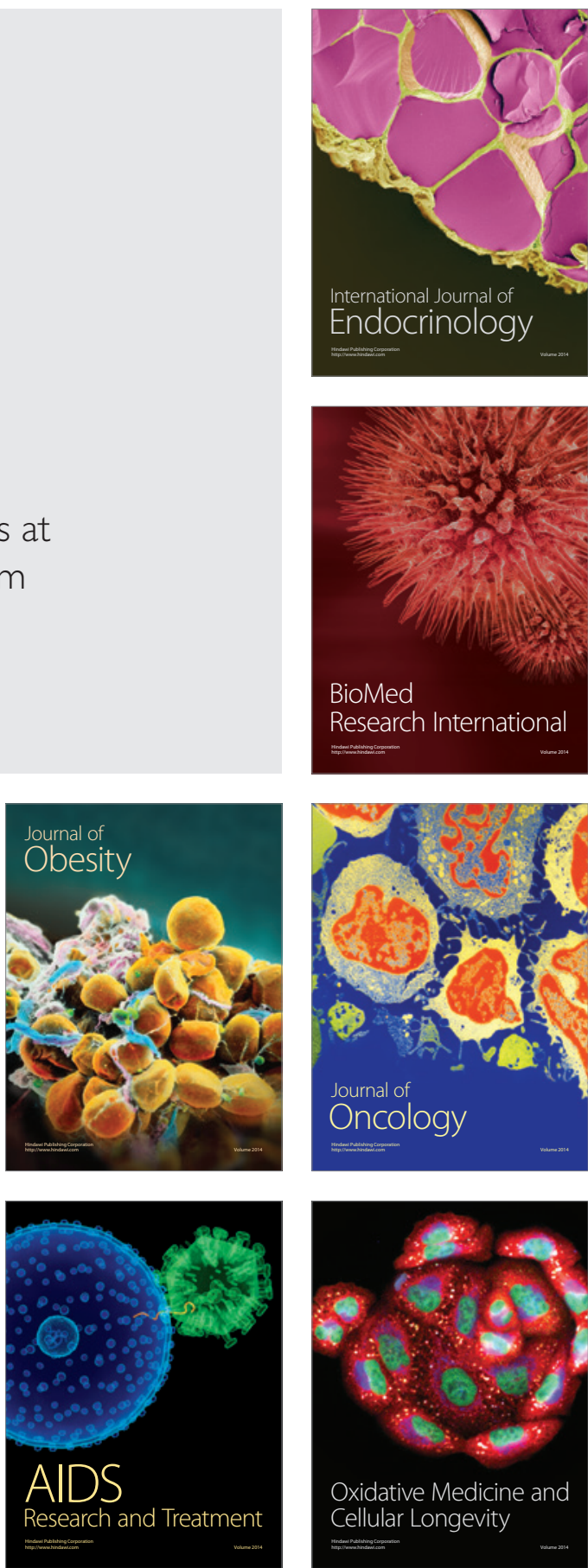